\title{
Kinetic analysis of bioorthogonal reaction mechanisms using Raman microscopy $\dagger$
}

\author{
William J. Tipping, (D) a Martin Lee, (D) b Valerie G. Brunton, ${ }^{b}$ \\ Guy C. Lloyd-Jones (iD a and Alison N. Hulme (D) *a
}

Received 3rd May 2019, Accepted 18th June 2019

DOI: $10.1039 / \mathrm{c} 9 \mathrm{fd} 00057 \mathrm{~g}$

Raman spectroscopy is well-suited to the study of bioorthogonal reaction processes because it is a non-destructive technique, which employs relatively low energy laser irradiation, and water is only very weakly scattered in the Raman spectrum enabling live cell imaging. In addition, Raman spectroscopy allows species-specific label-free visualisation; chemical contrast may be achieved when imaging a cell in its native environment without fixatives or stains. Combined with the rapid advances in the field of Raman imaging over the last decade, particularly in stimulated Raman spectroscopy (SRS), this technique has the potential to revolutionise our mechanistic understanding of the biochemical and medicinal chemistry applications of bioorthogonal reactions. Current approaches to the kinetic analysis of bioorthogonal reactions (including heat flow calorimetry, UV-vis spectroscopy, fluorescence, IR, NMR and MS) have a number of practical shortcomings for intracellular applications. We highlight the advantages offered by Raman microscopy for reaction analysis in the context of both established and emerging bioorthogonal reactions, including the copper(I) catalysed azide-alkyne cycloaddition (CUAAC) click reaction and Glaser-Hay coupling.

\section{Introduction}

Bioorthogonal chemistries have been rapidly adopted both in traditional synthetic chemistry and as a means to site-specifically label biomolecules inside cells. ${ }^{1-5}$ More recently their use has been proposed as a means to both construct and de-cage complex drug molecules in vivo as a new therapeutic modality. ${ }^{6,7}$ Critical to the success of reactants that couple under bioorthogonal conditions are that they are mutually reactive but do not cross-react, or interact, with other biological functionalities or reactions in a cell; that they are stable and non-toxic

${ }^{a}$ EaStCHEM School of Chemistry, The University of Edinburgh, Joseph Black Building, David Brewster Road, Edinburgh, EH9 3FJ, UK. E-mail: Alison.Hulme@ed.ac.uk

${ }^{b}$ Edinburgh Cancer Research Centre, MRC Institute of Genetics and Molecular Medicine, The University of Edinburgh, Crewe Road South, Edinburgh, EH4 2XR, UK

$\dagger$ Electronic supplementary information (ESI) available: Fig. S1-S7 and Tables S1-S4. See DOI: 10.1039/c9fd00057g. Primary data files can be found at https://doi.org/10.7488/ds/2576 
in physiological settings; and that their mutual reaction is highly specific and fast. ${ }^{1}$ Rapid reaction rates are required particularly to monitor fast intracellular processes and also where the intracellular abundance of the reacting species is comparatively low. ${ }^{2}$ However, despite many studies of these reactions in solution (illustrated for the bioorthogonal reactions of alkynes in Fig. 1), ${ }^{2,45}$ current approaches to their kinetic analysis are limited in their intracellular application by the need for coupling to a specific substrate (for fluorescence), ${ }^{\mathbf{8}, 9}$ the low spatial resolution (for $\mathrm{IR}^{\mathbf{1 0}}$ and $\mathrm{MS}^{\mathbf{1 1}}$ ), and the concentrations required (for NMR). ${ }^{\mathbf{1 2}}$ Differences arising from intracellular macromolecular crowding, ${ }^{13}$ variations in $\mathrm{pH}$ across cell populations and within individual cells, ${ }^{\mathbf{1 4}}$ and the sequestration of substrates into cellular structures or organelles ${ }^{15}$ are poorly accounted for by bulk in vitro solution phase analysis, necessitating the urgent development of techniques which might be applicable in an in cellulo or in vivo microenvironment.

Raman is well-suited to the study of bioorthogonal reaction processes because it is a non-destructive technique, which employs relatively low energy laser irradiation, and water is only very weakly scattered in the Raman spectrum enabling live cell imaging. ${ }^{16}$ In addition, Raman spectroscopy allows species-specific labelfree visualisation; chemical contrast may be achieved when imaging a cell in its native environment without fixatives or stains. Combined with the rapid advances in the field of Raman imaging over the last decade, ${ }^{17}$ most notably in coherent techniques such as stimulated Raman scattering (SRS), this has the potential to revolutionise our mechanistic understanding of the biochemical and medicinal chemistry applications of bioorthogonal reactions.

We chose to focus our study on the reactions of alkynes, as they are widely used in bioorthogonal chemistry ${ }^{2-5}$ and have been used to probe biological processes, such as DNA, RNA and protein synthesis, effectively using Raman spectroscopy and SRS microscopy. ${ }^{18}$ Two notable bioorthogonal reactions of alkynes are: (a) the copper(I) catalysed azide-alkyne cycloaddition (CuAAC) click reaction (Fig. 1A(i)); ${ }^{19,20}$ and (b) the Glaser-Hay reaction (Fig. 1A(ii)). ${ }^{21,22}$ These two coppercatalysed reactions provide complementary reaction pathways from a terminal alkyne, and are thought to occur (in solution) at comparable, or slower, rates than
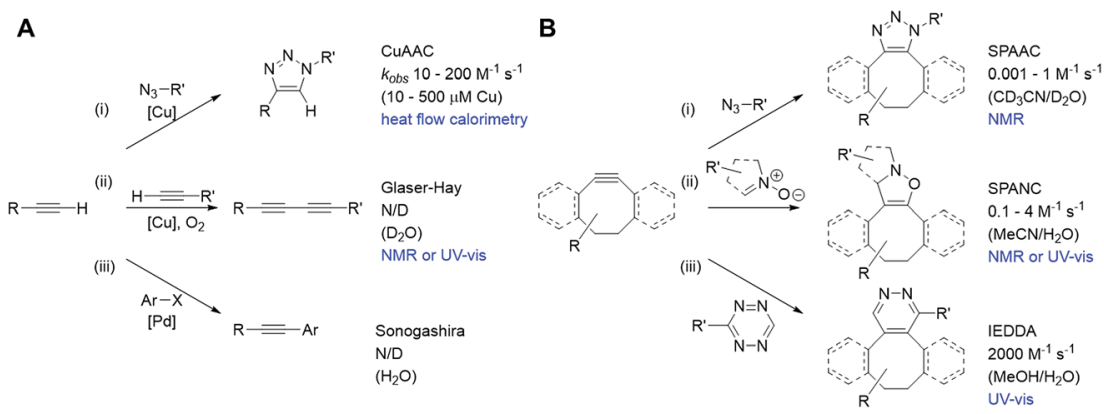

Fig. 1 Bioorthogonal reactions of terminal alkynes (A) and strained alkynes (B), with approximate rate constants in aqueous based media (N/D = not determined). (A) (i) Copper(I) catalysed azide-alkyne cycloaddition (CuAAC); ${ }^{23}$ (ii) Glaser-Hay reaction; ${ }^{24}$ (iii) copper-free Sonogashira reaction. ${ }^{25}$ (B) (i) Strain-promoted azide-alkyne cycloaddition $(S P A A C) ; 26$ (ii) strain-promoted alkyne nitrone cycloaddition (SPANC); ${ }^{26}$ (iii) inverse electron demand Diels-Alder (IEDDA). ${ }^{27}$ 
other bioorthogonal reactions of terminal alkynes and the strain-promoted cycloaddition reactions of cyclooctyne derivatives with dipoles or tetrazines (Fig. 1B). ${ }^{23-27}$

The CuAAC reaction has emerged as a leading example of 'click chemistry', a term developed by Sharpless et al. in 2001 to describe near-perfect bond-forming reactions which are useful for rapid assembly of molecules with desired function. ${ }^{28}$ The use of $\mathrm{Cu}(\mathrm{I})$ salts, or a $\mathrm{Cu}$ (II) precursor in combination with a reducing agent to provide catalytically-active copper species in situ has been shown to mediate azide-alkyne cycloaddition with high rates of reaction. Current mechanistic understanding of the CuAAC reaction (Fig. 2A) supports a model with two chemically equivalent copper atoms working together to bring about the regioselective formation of 1,4-substituted 1,2,3-triazoles. ${ }^{29}$ Formation of the copper acetylide is turnover rate-limiting, thus strategies which aid alkyne deprotonation accelerate the CuAAC reaction. ${ }^{30}$ When particularly acidic alkynes are used, a switch in the rate limiting step to azide ligation/migratory insertion is observed. ${ }^{31}$ Heat flow calorimetry has been used extensively in detailed mechanistic studies of the CuAAC reaction, which clearly does not translate to an in cellulo or in vivo environment.

Oxidative homocoupling of copper(I)-phenylacetylide upon exposure to air was first observed in 1869 by Carl Glaser, ${ }^{32}$ and consequently the reaction bears his name. Modifications to the initial Glaser coupling conditions sought to form the copper(I) acetylide in situ; ${ }^{33}$ in the Hay modification, oxidative acetylinic coupling was demonstrated in an oxygen environment in the presence of catalytic amounts of $\mathrm{CuCl}$ and the bidentate ligand, TMEDA. ${ }^{21}$ The Glaser-Hay reaction is emerging as a bioorthogonal reaction which is particularly useful for producing bioconjugates where the reduced steric demands of a bisalkyne linker are critical. The mechanism of the Glaser-Hay reaction has been studied, using a variety of analytical techniques. ${ }^{\mathbf{2 4 3 4 , 3 5}}$ An early report by Bohlmann et al. examining the homocoupling of terminal acetylenes in $\mathrm{MeOH}: \mathrm{H}_{2} \mathrm{O}(80: 20)$ at $\mathrm{pH} 3(\mathrm{HCl})$ identified the formation of a dicopper(II)-diacetylide complex as the rate-limiting step in the observed second-order kinetics using UV absorption spectroscopy. ${ }^{\mathbf{3 4}}$ The proposed mechanism involved reductive elimination of this species to yield the 1,3-diyne product (Fig. 2B). A more recent DFT study broadly supports this mechanism, but suggests that (as for the CuAAC reaction) the turnover ratelimiting step corresponds to the Cu-coordinated alkyne deprotonation. ${ }^{36}$ In

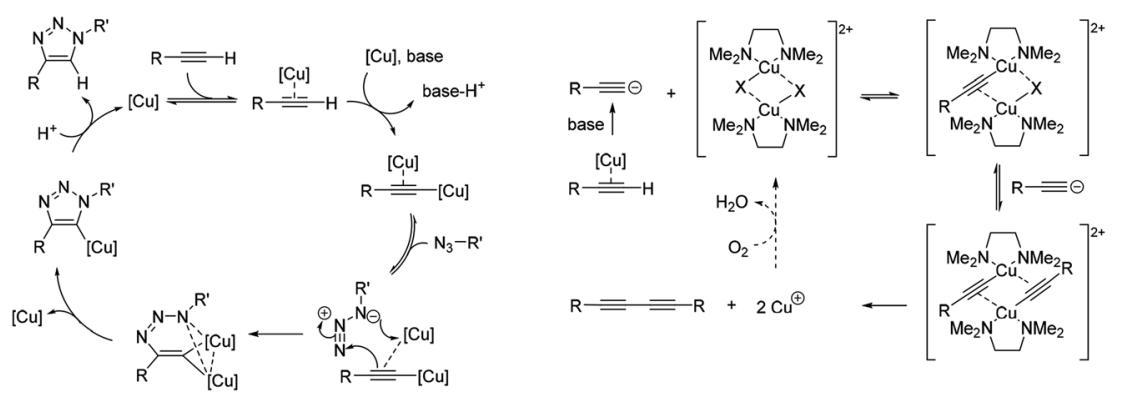

Fig. 2 Simplified mechanisms for the catalytic cycle of (A) the CuAAC reaction, ${ }^{29 a}$ and (B) the Glaser-Hay reaction. ${ }^{34}$ 
contrast, studies combining NMR and UV spectroscopy to probe the reaction of terminal acetylenes in $\mathrm{D}_{2} \mathrm{O}$ or $\mathrm{CH}_{2} \mathrm{Cl}_{2}$ have suggested that the mechanism involves a mono-nuclear $\mathrm{Cu}^{2+}$ intermediate. ${ }^{24,35}$ Again, the analytical techniques used to study the Glaser-Hay reaction to date do not readily translate to a more biological setting. Thus this provided a second reaction against which we could test our Raman spectroscopic approach.

\section{Results and discussion}

\section{Establishing Raman spectroscopy as a method to follow bioorthogonal reactions}

Real-time chemical reaction monitoring has been reported using both infrared (IR) and Raman spectroscopy. For a molecule to be IR active, there must be an accompanying change in dipole moment of the chemical bond as a result of absorption of the incident IR radiation. The CuAAC reaction has been studied previously using IR spectroscopy in an organic solvent (DMF) following the decay of the azide peak at $2096 \mathrm{~cm}^{-1} \cdot{ }^{10}$ Here, we show that the CuAAC reaction can be followed by IR spectroscopy in an aqueous solvent mixture (Fig. S1†), but not one that is compatible with biological cells. In general, functional groups which generate a strong peak in an IR spectrum tend to be weaker in Raman and vice versa. Raman active shifts are a result of a change in bond polarisation upon interaction of monochromatic light. Raman scattering, therefore, is detected as an inelastic scattered photon, but only 1 in $10^{8}$ photons undergo Raman scattering. ${ }^{37}$ Despite this, even low intensity vibrations (e.g. $\left.\mathrm{C}-\mathrm{H}\right)$ can provide signals for imaging purposes if visualised at high enough concentrations. Spectroscopically bioorthogonal functional groups, including alkyne $(\mathrm{C} \equiv \mathrm{C})$, nitrile $(\mathrm{C} \equiv \mathrm{N})$ and deuterated groups $(\mathrm{C}-\mathrm{D})$, produce peaks in the cellular-silent region of the Raman spectrum, between $1800-2800 \mathrm{~cm}^{-1} \cdot{ }^{17,18}$ Of these, the alkyne-containing thymidine analogue, EdU (Fig. 3, 1), is the most widely studied small molecule for Raman imaging applications. EdU is used as a probe for DNA synthesis in proliferating cells, using CuAAC conjugation with a fluorescent probe ${ }^{38}$ or biotin group for pull-down experiments, ${ }^{39}$ and more recently, inherent visualisation of the alkyne group present within EdU at $2120 \mathrm{~cm}^{-1}$ has been achieved in a single step using Raman and SRS imaging approaches (Fig. 3). ${ }^{18}$ SRS imaging provides fast acquisition rates (up to video rate speeds) and can generate images based on the inherent chemical contrast of the cell. Fig. 3B shows SRS images of the $\mathrm{CH}_{3}$ (2939 $\mathrm{cm}^{-1}$, proteins) and $\mathrm{CH}_{2}\left(2844 \mathrm{~cm}^{-1}\right.$, lipids $)$ signal in HeLa cells. Additionally, the incorporation of EdU is detected in the nucleus of the cells at $2120 \mathrm{~cm}^{-1}$.

Reaction time-course experiments were first measured in solution-phase using Raman spectroscopy. To assess the feasibility of using a Raman spectral approach to monitor the reaction progress of bioorthogonal transformations, initial investigations focussed upon the CuAAC reaction between EdU (1) and biotinPEG3-azide (2) in the presence of $\mathrm{CuSO}_{4}$ and ascorbic acid in DMSO(aq.). The intense Raman signal of the EdU alkyne (at $2120 \mathrm{~cm}^{-1}$ ) was preferred for reaction monitoring, over the weak Raman signal associated with the azide (at $2096 \mathrm{~cm}^{-1}$ ) (Fig. S2 $\dagger$ ). The time-course dataset was normalised to the intensity of the Raman peak of the DMSO reaction solvent at $1418 \mathrm{~cm}^{-1}$ (DMSO CH def.) which enabled direct comparison of the relative peak intensities and the peak positions in 
A

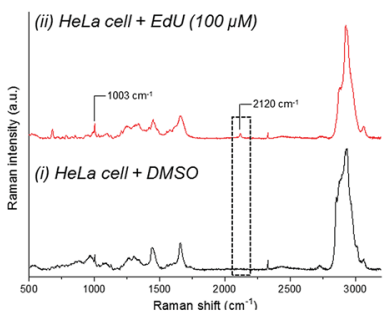

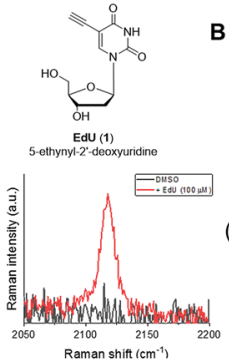

B (i)

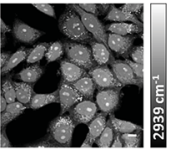

(iii)

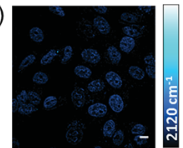

(ii)

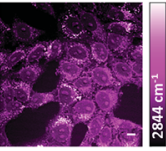

(iv)

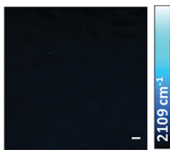

Fig. 3 Detection of alkyne-labelled DNA using EdU (1) and Raman imaging. (A) Spontaneous Raman spectroscopy of single fixed HeLa cells treated with (i) DMSO and (ii) EdU $(100 \mu \mathrm{M}, 18 \mathrm{~h}) .^{18}$ The spectra were normalised to the intensity of the peak at $1003 \mathrm{~cm}^{-1}$ (phenylalanine ring breathing mode), scaled between 1000-20 000 counts and offset for clarity. Peak annotations: $1003 \mathrm{~cm}^{-1}$ (phenylalanine ring breathing mode); $2120 \mathrm{~cm}^{-1}$ $(\mathrm{C} \equiv \mathrm{C}, \mathrm{EdU})$. Raman spectra acquired using $\lambda_{\mathrm{ex}}=532 \mathrm{~nm}$ using a $50 \times$ objective lens and $30 \mathrm{~s}$ integration time. Inset: chemical structure of EdU (top) and expansion of the EdU alkyne region (2050-2220 $\mathrm{cm}^{-1}$ indicated by the dashed box; bottom). (B) SRS imaging of HeLa cells treated with EdU (100 $\mu \mathrm{M}, 18 \mathrm{~h}) .^{18}$ SRS images were acquired at (i) $2939 \mathrm{~cm}^{-1}$ $\left(\mathrm{CH}_{3}\right)$, (ii) $2844 \mathrm{~cm}^{-1}\left(\mathrm{CH}_{2}\right)$, (iii) $2120 \mathrm{~cm}^{-1}\left(\mathrm{C} \equiv \mathrm{C}, \mathrm{EdU}\right.$ ) and (iv) $2109 \mathrm{~cm}^{-1}$ (cell-silent region). SRS images were acquired using $1024 \times 1024$ pixels and $20 \mu$ s pixel dwell time. False colours were applied to different detection wavenumbers. Scale bars: $10 \mu \mathrm{m}$.

Raman spectra at each individual timepoint. The spectra are presented in Fig. 4A. In the course of the reaction, the intensity of the Raman peak at $2120 \mathrm{~cm}^{-1}$ (EdU, $\mathrm{C} \equiv \mathrm{C})$ decreases to the baseline level. Additionally, a shift in the peak at $1624 \mathrm{~cm}^{-1}$ to $1646 \mathrm{~cm}^{-1}$ indicates a change in the local bonding environment surrounding the amide $\mathrm{C}=\mathrm{O}$ of EdU upon formation of the triazole product. Integration of the alkyne peak at $2120 \mathrm{~cm}^{-1}$ indicates that the reaction reaches completion within $40 \mathrm{~min}$, whilst in the absence of $\mathrm{Cu}$ catalyst, there is only very

A

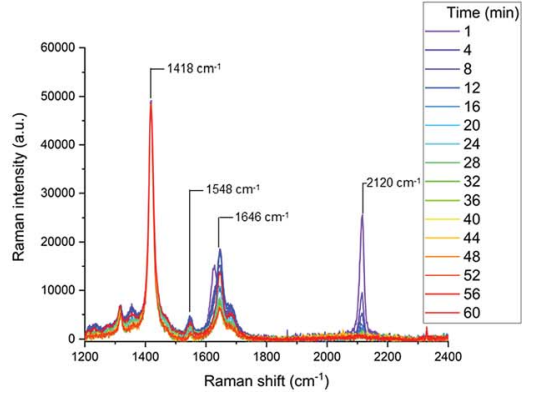

B

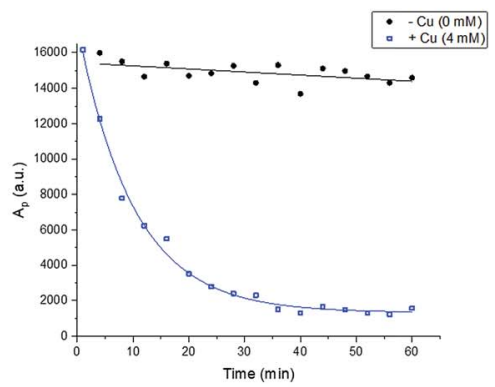

Fig. 4 Reaction monitoring of the CuAAC reaction between EdU (1) and biotin-PEG3azide (2) using Raman spectroscopy. (A) Raman spectra of a reaction mixture comprising $\mathrm{EdU}(50 \mathrm{mM})$, biotin-PEG3-azide $(50 \mathrm{mM}), \mathrm{CuSO}_{4}(4 \mathrm{mM})$ and ascorbic acid $(20 \mathrm{mM})$ in DMSO(aq.). An aliquot of the reaction mixture was removed at each timepoint and the individual Raman spectra presented between 0-60 min. Spectra were acquired using $\lambda_{\text {ex }}=532 \mathrm{~nm}$ for $20 \mathrm{~s}$ using a $20 \times$ objective lens. The Raman spectra were normalised to the intensity of the peak at $1418 \mathrm{~cm}^{-1}$ (DMSO CH def.). (B) Integration analysis of the normalised Raman peak at $2120 \mathrm{~cm}^{-1}(\mathrm{C} \equiv \mathrm{C}$, EdU) for the reaction presented in (A) (blue squares, + $\mathrm{Cu}(4 \mathrm{mM})$ with exponential fitting applied) and a control reaction (black circles, $-\mathrm{Cu}$, linear fitting) where $[\mathrm{Cu}]=0 \mathrm{mM} . A_{\mathrm{p}}=$ peak area $(a) 2120 \mathrm{~cm}^{-1}$. 
marginal reduction in the alkyne signal over 60 min (Fig. 4B). An advantage of the Raman spectral approach detailed here over NMR-based reaction monitoring methods is that extremely small reaction volumes can be employed; here the reactions were performed using $25 \mu \mathrm{L}$ total volume at $t=0 \mathrm{~min}$.

\section{Kinetic analysis of the CuAAC click reaction}

For more demanding applications, including CuAAC reactions in the cellular environment, the use of $\mathrm{Cu}$-coordinating ligands has been found to accelerate the CuAAC reaction even further, up to several thousand times more than the ligandfree process. ${ }^{23}$ The requirement for Cu-coordinating ligands was particularly evident for bioconjugation reactions involving biological molecules, which impose specific demands in that they must be chemoselective, biocompatible, operate in aqueous environments at low reactant concentrations and induce fast catalyst turnover. ${ }^{\mathbf{4 0}}$ A number of Cu-coordinating ligands have been developed for CUAAC reactions in cells, including THPTA (Fig. 5) and TBTA (Fig. 5); these are known to significantly accelerate the CuAAC reaction and stabilize the $\mathrm{Cu}(\mathrm{I})$ oxidation state in aqueous mixtures. ${ }^{41}$

Having established Raman spectroscopy as a suitable method for following the progress of the ligand-free CuAAC reaction, we next sought to perform a kinetic analysis of the ligand-accelerated CuAAC reaction. Firstly, the initial $[\mathrm{Cu}]_{\text {tot }}$ was varied between 0-15 mM (with equimolar [THPTA]) using a fixed concentration of both the EdU (100 mM, alkyne) and biotin-PEG3-azide (100 mM, azide) reagents.
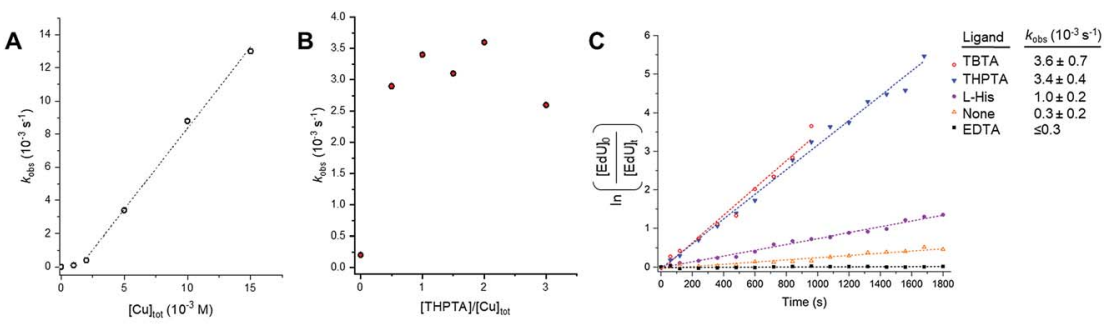

D
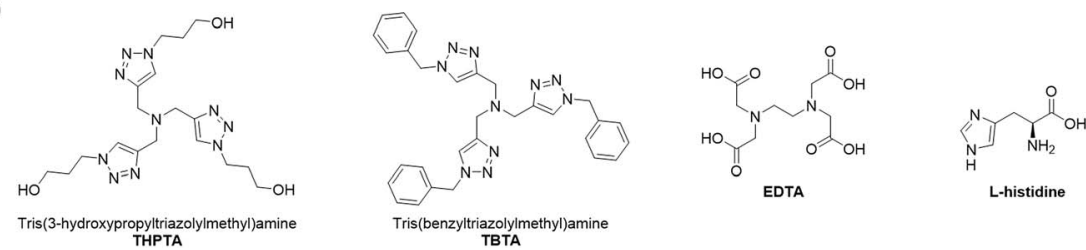

Fig. 5 Investigating catalyst composition effects on the kinetics of the CuAAC reaction between EdU and biotin-PEG3-azide in DMSO/ $\mathrm{H}_{2} \mathrm{O} 3: 2 \mathrm{v} / \mathrm{v}$. (A) Plot of $k_{\text {obs }}$ as a function of $[\mathrm{Cu}]_{\text {tot, }}$ showing a first-order dependence on $[\mathrm{Cu}]_{\text {tot. }}$ A linear fitting is only applied between $[\mathrm{Cu}]_{\text {tot }}=2-15 \mathrm{mM}$, due to the suspected presence of low concentrations of inhibitors in the reactants. Experimental conditions are described in entry 1, Table 1. Tabulated data with $k_{\text {obs }} \pm 0.5$ RMSE, see Table S1. $\uparrow$ (B) Plot of $k_{\text {obs }}$ as a function of $[\text { THPTA]/[Cu }]_{\text {tot }}$ ratio. Experimental conditions are described in entry 2, Table 1. Tabulated data with $k_{\text {obs }} \pm 0.5$ RMSE, see Table S2. $\dagger$ (C) Plot of the CuAAC reaction with different CUAAC ligands with $k_{\text {obs }} \pm 0.5$ RMSE. Experimental conditions are described in entry 3 , Table 1. (D) Chemical structure of the Cu(I) ligands, THPTA, TBTA, EDTA and L-histidine. 
Table 1 Experimental conditions for the CuAAC reaction between EdU and biotin-PEG3azide

\begin{tabular}{lcllll}
\hline Entry & $\begin{array}{l}{[\mathrm{EdU}]} \\
(\mathrm{mM})\end{array}$ & $\begin{array}{l}\text { Biotin-PEG3-azide } \\
(\mathrm{mM})\end{array}$ & $\begin{array}{l}{[\mathrm{NaAsc}]} \\
(\mathrm{mM})\end{array}$ & $\begin{array}{l}{\left[\mathrm{CuSO}_{4}\right]} \\
(\mathrm{mM})\end{array}$ & $\begin{array}{l}{[\mathrm{THPTA}]} \\
(\mathrm{mM})\end{array}$ \\
\hline 1 & 100 & 100 & 100 & $0-15$ & $0-15$ \\
2 & 100 & 100 & 100 & 5 & $2.5-15$ \\
3 & 100 & 100 & 100 & 5 & $5^{a}$ \\
\multicolumn{7}{l}{} \\
\multicolumn{7}{l}{ Ligand varied between THPTA, TBTA, L-histidine and EDTA. } \\
\hline
\end{tabular}

A plot of $k_{\text {obs }}$ as a function of [Cu $]_{\text {tot }}$ showed a first-order dependence on [Cu $]_{\text {tot }}$ (Fig. 5A). This observation is consistent with the recently reported empirical rate law for the Cu-catalysed reaction of phenylacetylene with benzyl azide determined using heat-flow calorimetry. ${ }^{29 b}$ Additionally, a non-linear correlation at $[\mathrm{Cu}]$ $\leq 2 \mathrm{mM}$ indicated the presence of low concentrations of inhibitors in the reactants. Next, we investigated the specific activity for the CuAAC reaction between EdU and biotin-PEG3-azide accelerated by THPTA. A plot of $k_{\mathrm{obs}}$ as a function of the $[$ THPTA $] /[\mathrm{Cu}]$ ratio is provided in Fig. $5 \mathrm{~B}$. In the absence of THPTA ligand, the reaction rate is markedly reduced, and a maximum rate-enhancing effect of the THPTA ligand was found at [THPTA $]:[\mathrm{Cu}] \geq 0.5 .{ }^{23}$ Finally, the nature of the $\mathrm{Cu}-$ coordinating ligand was varied (Fig. 5C). The rate-enhancement by different ligands followed the order THPTA $\approx$ TBTA $\gg$ L-histidine, with no reaction in the presence of EDTA. ${ }^{42}$ Taken together, these results indicate that Raman spectroscopy is a simple and effective technique for profiling the bioorthogonal ligandassisted CuAAC reaction in solution-phase.

\section{Kinetic analysis of the Glaser-Hay reaction}

Like the CuAAC reaction, the Glaser-Hay reaction has also been used in bioconjugation applications. In a seminal report, the Glaser-Hay reaction was used to generate protein bioconjugates under aqueous conditions, through sitespecific incorporation of an alkyne-containing unnatural amino acid in an expressed protein and coupling under modified Glaser-Hay conditions. ${ }^{43}$ Additional studies have used Glaser-Hay bioconjugation for protein immobilisation ${ }^{\mathbf{4 4}}$ and the synthesis of natural products using solid-supports. ${ }^{45}$ Given the increasing interest in the Glaser-Hay reaction for bioconjugation, we attempted to study aspects of its reaction kinetics using Raman spectroscopy to enable further optimisation of the reaction for biological applications. We chose to study the homodimerisation of propargyl choline (3) as a first step towards this goal (Fig. 6A). Propargyl choline is an alkyne-containing choline metabolite that was developed for the imaging of choline-containing phospholipids in vivo using CuAAC conjugation. ${ }^{46}$ More recently, however, it has been detected in living cells and tissues using SRS microscopy, which localises the metabolically-incorporated alkyne directly without the need for a second chemical reaction. ${ }^{18}$ The Raman spectrum of propargyl choline (as its bromide salt) shows an intense peak at $2131 \mathrm{~cm}^{-1}$ associated with the alkyne group (Fig. S3†). Glaser-Hay reaction timecourse experiments in DMSO solution (Fig. 6B) indicated that in the presence of $7.5 \mathrm{~mol} \%$ of CuI/TMEDA catalyst, the formation of the homodimer butadiyne 
A

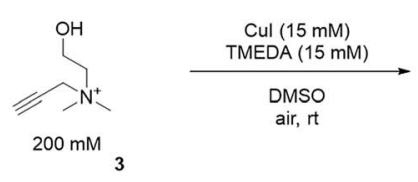

B

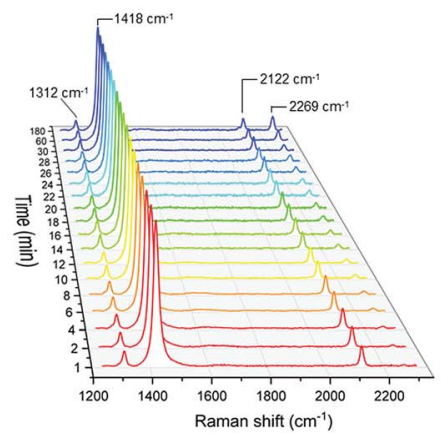

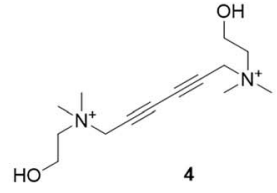

C

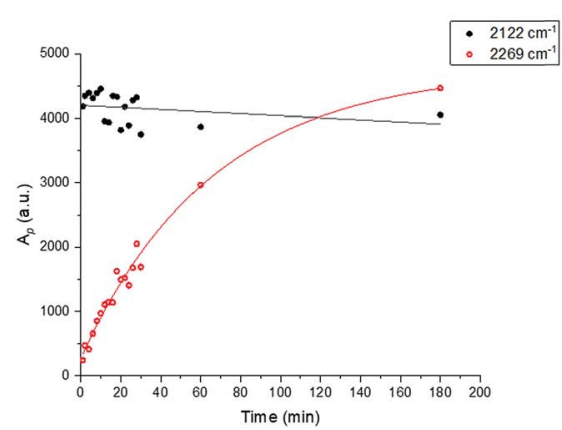

Fig. 6 Reaction monitoring of the Glaser-Hay homocoupling of propargyl choline using Raman spectroscopy. (A) Glaser-Hay reaction of propargyl choline (200 mM) using Cul (15 mM, $7.5 \mathrm{~mol} \%$ ) and TMEDA (15 mM, $7.5 \mathrm{~mol} \%)$ in DMSO. (B) Raman spectra of the reaction mixture in $(A)$ acquired at the indicated timepoints following addition of the Cul/ TMEDA catalyst. An aliquot of the reaction mixture was removed at each timepoint and the individual Raman spectra presented between 0-180 min. Spectra were acquired using $\lambda_{\text {ex }}=532 \mathrm{~nm}$ for $20 \mathrm{~s}$ using a $20 \times$ objective lens. The Raman spectra were normalised to the intensity of the peak at $1418 \mathrm{~cm}^{-1}$ (DMSO CH def.). (C) Integration analysis of the Raman peaks at $2122 \mathrm{~cm}^{-1}$ (propargyl choline) and $2269 \mathrm{~cm}^{-1}$ (dimer) presented in (B). $A_{\mathrm{p}}=$ peak area (a $2122 \mathrm{~cm}^{-1} / 2269 \mathrm{~cm}^{-1}$. The lines through the data are merely a guide to the eye, not kinetic fitting.

product (4) was observed as a discrete peak at $2269 \mathrm{~cm}^{-1}$ (with the starting material detected at $2122 \mathrm{~cm}^{-1}$ ). Integration of the relative peak areas at $2122 \mathrm{~cm}^{-1}$ and $2269 \mathrm{~cm}^{-1}$ shows a significant increase in the intensity of the product as a function of reaction time, whilst the intensity of the starting material is seen to decrease (Fig. 6C). The relative intensity differences for the two alkyne signals reflects the observation that bis-alkynes have an overall higher Raman scattering cross-section compared to single, terminal alkynes (Fig. S4†). This experiment indicated that Raman spectroscopy could be used to follow the progress of the Glaser-Hay reaction in solution. The detection of the butadiyne product at a discrete Raman shift is a major advantage of this approach, as the relative intensities of both the starting material consumption and product formation could be assessed quantitatively in the same spectral acquisition. Furthermore, the ability to detect both alkyne components within the cellularsilent region of the Raman spectrum may facilitate optimisation of Glaser-Hay bioconjugations; for example, in determining the reaction yield.

We next sought to study the kinetics of the Glaser-Hay reaction and used the homodimerisation of phenylacetylene (PA) as a model reaction. We chose PA because it has been widely used in this context, most recently in a DFT study of the reaction. ${ }^{36}$ The study was performed on a $20 \mu \mathrm{L}$ scale, with air constantly bubbling through the reaction mixture. Initially, phenylacetylene $(100 \mathrm{mM})$ was reacted in the presence of $\mathrm{CuI}(10 \mathrm{mM})$ and TMEDA $(10 \mathrm{mM})$ in DMSO. In the 
course of the reaction, the intensity of the PA alkyne signal at $2102 \mathrm{~cm}^{-1}$ is seen to decrease, whilst the intensity of the product signal at $2218 \mathrm{~cm}^{-1}$ greatly increases (Fig. S5A $\dagger$ ). ${ }^{47}$ Additionally, new peaks are generated at $1341 \mathrm{~cm}^{-1}$ and $1496 \mathrm{~cm}^{-1}$, whilst the intensity of the peak at $1597 \mathrm{~cm}^{-1}$ also increases. These observations are indicative of the formation of the 1,4-bisphenyl-1,3-butadiyne product (Fig. S5B $\dagger$ ). Using the normalised peak area for the Raman signals of PA (at $2102 \mathrm{~cm}^{-1}$ ) and the butadiyne product (at $2218 \mathrm{~cm}^{-1}$ ), the kinetics of the GlaserHay reaction were assessed in response to varying $[\mathrm{Cu}]_{\text {tot }},[\mathrm{PA}], \mathrm{Cu}$ source and $\mathrm{Cu}-$ coordinating ligand (Fig. S6†). Firstly, the [PA] was fixed at $100 \mathrm{mM}$ and $[\mathrm{Cu}]_{\text {tot }}$ varied between 0-20 mM. Empirical second-order rate constants, $k_{\text {obs }}$, were estimated by linear correlation of $1 /[\mathrm{PA}]$ versus time; i.e. rate $\approx k_{\mathrm{obs}}[\mathrm{PA}]^{2}$. A plot of $k_{\mathrm{obs}}$ versus $[\mathrm{Cu}]_{\mathrm{tot}}{ }^{2}$ resulted in a linear relationship, i.e. $k_{\mathrm{obs}} \approx k[\mathrm{Cu}]_{\mathrm{tot}}^{2}$ (Fig. $7 \mathrm{~A}$ ). Additionally, the [PA] was varied between 50-150 mM, with [Cu] and [TMEDA] fixed at $10 \mathrm{mM}$, yielding consistent $k_{\text {obs }}$ values over the concentration range tested (Fig. S7 $\dagger$ ). The effect of varying the ratio [TMEDA $] /[\mathrm{Cu}]$ was also investigated (Fig. 7B) and it was found that excess TMEDA causes inhibition of the reaction. The empirical rate equation is thus described by:

$$
\text { Rate } \approx k_{\mathrm{obs}}[\mathrm{PA}]^{2} \text {; where } k_{\mathrm{obs}} \approx 0.5[\mathrm{Cu}]_{\mathrm{tot}}^{2} \mathrm{M}^{-1} \mathrm{~s}^{-1}
$$

These results indicate a second-order dependence in both the copper and PA. Further studies investigated the catalyst composition effects; CuI showed an overall higher rate of reaction than $\mathrm{Cu}(\mathrm{OAc})_{2}$ (Fig. 7C), whilst TMEDA gave

A

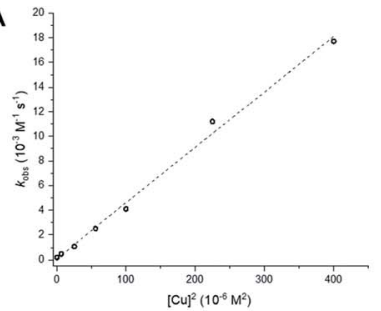

C

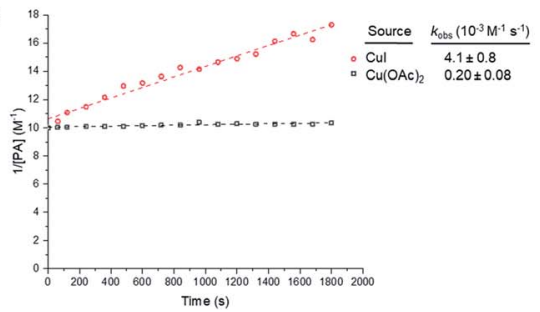

B
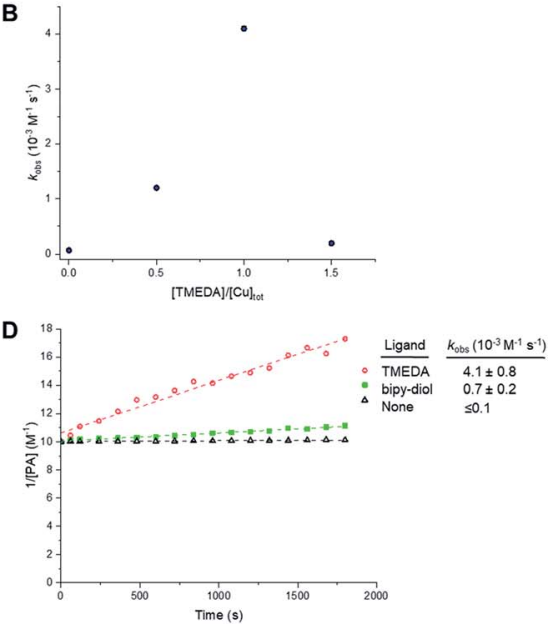

Fig. 7 Empirical correlations for the kinetics of the Glaser-Hay homocoupling of phenylacetylene (PA). Experimental conditions are tabulated in Table S3. $\dagger$ (A) Correlation of the observed second-order rate constant with total [Cu]. Experimental conditions are described in entry 1, Table S3. $\uparrow$ Tabulated data with $k_{\text {obs }} \pm 0.5$ RMSE, see Table S4. $\uparrow$ (B) Effect of $\mathrm{Cu}$ : TMEDA ratio on observed second-order rate constant. Experimental conditions are described in entry 2, Table S3. $\dagger$ Tabulated data with $k_{\mathrm{obs}} \pm 0.5 \mathrm{RMSE}$, see Table S5. $\dagger$ Empirical second-order kinetic analysis of Glaser-Hay reactions with various $\mathrm{Cu}$-sources (C), and ligand (D) with $k_{\text {obs }} \pm 0.5$ RMSE. Experimental conditions are described in entries 3 and 4 , Table S3. $\dagger$ 


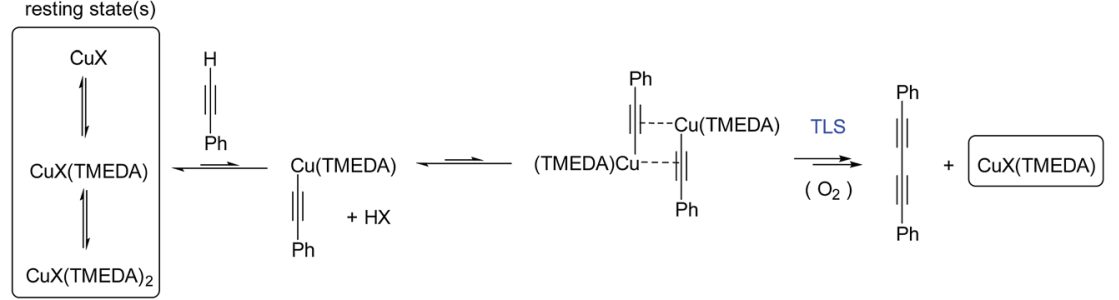

Fig. 8 Mechanism for the Glaser-Hay reaction consistent with kinetic data obtained by Raman spectral analysis. TLS $=$ turnover rate-limiting step.

a higher rate of reaction than bipy-diol (Fig. 7D). The implications of these findings are summarised in Fig. 8. In terms of mechanism, the data are consistent with an equilibrium between (TMEDA)CuX and PA, to afford a complex [Cu.PA] in which there is one TMEDA, or in which the TMEDA is lost as [TMEDA $\cdot \mathrm{H}]^{+} \mathrm{X}^{-}$, coupled to a second equilibrium involving two $[\mathrm{Cu} \cdot \mathrm{PA}]$, presumably generating one $\left[\mathrm{Cu}_{2} \cdot \mathrm{PA}_{2}\right]$ intermediate, and then a turnover rate-limiting irreversible reaction of $\left[\mathrm{Cu}_{2} \cdot \mathrm{PA}_{2}\right]$ that directly, or indirectly, generates product and regenerates $\mathrm{CuX}$ or (TMEDA)CuX. This scenario is broadly consistent with the mechanism proposed by Maseras et al. using DFT analysis (Fig. 2). ${ }^{36}$ Taken together, these data indicate that Raman spectroscopy is a useful method for profiling the Glaser-Hay reaction.

\section{Conclusions}

The studies described here indicate that Raman spectroscopy is ideally suited to analysing the kinetics of alkyne-based reactions. The intense alkyne signal in the Raman spectrum is well resolved from other solvent peaks in the fingerprint region $\left(<1700 \mathrm{~cm}^{-1}\right)$, and can thus be used to monitor the consumption of a starting material (i.e. EdU in the CuAAC reaction) or the generation of a product (i.e. butadiyne in the Glaser-Hay reaction). With the emergence of portable and in-line Raman instrumentation, Raman spectroscopy is expected to serve as a useful technique for profiling chemical reactions at scale. For the purposes of studying reactions at the microscopic level, the small sample volumes required for Raman analysis and the ability to use advanced Raman imaging systems (e.g. SRS microscopy) to provide detailed analysis of cellular features will enable rigorous kinetic investigations at the sub-cellular level. This approach would thus enhance current understanding of bioconjugation reactions in the cellular environment, which would enable a thorough understanding of both the intracellular chemistry and biology as a result.

\section{Materials and methods}

\section{Infra-red spectroscopy}

FT infra-red (FTIR) spectra were recorded on a Shimadzu IRAffinity-1 spectrophotometer with a Pike Technologies horizontal ATR attachment, ZnSe lens single reflection ATR plate and Happ Genzel apodization. The recorded spectral range was $550-4000 \mathrm{~cm}^{-1}$. Data acquisition was performed over 10 scans. Spectral resolution for the system is $0.5 \mathrm{~cm}^{-1}$. 


\section{Raman spectroscopy}

The spontaneous Raman spectra were acquired using a confocal Raman spectrometer (inVia Raman microscope, Renishaw) at room temperature. A $297 \mathrm{~mW}$ (206 $\mathrm{mW}$ after objective) $785 \mathrm{~nm}$ diode laser or a $30 \mathrm{~mW} 532 \mathrm{~nm}$ laser excitation source was used to excite the sample through a $50 \times$, N.A. 0.75 objective, a $20 \times$, N.A. 0.40 objective or a $5 \times$, N.A. 0.12 objective (Leica Biosystems). The recorded spectral range for grating $1200 \mathrm{~g} \mathrm{~mm}^{-1}$ was $100-200 \mathrm{~cm}^{-1}$. The total data acquisition was performed for $60 \mathrm{~s}$ for spectra recorded at $\lambda_{\mathrm{ex}}=785 \mathrm{~nm}$ or $10 \mathrm{~s}$ for spectra recorded at $\lambda_{\mathrm{ex}}=532 \mathrm{~nm}$ using the WiRE software. Spectral resolution for the system is $0.5 \mathrm{~cm}^{-1}$. The spectra were baseline corrected using the Baseline Subtract function available on WiRE ${ }^{\mathrm{TM}}$ software. Peak normalisation was performed using Origin Lab Data Analysis and Graphing software. Peak integration was performed on Origin using the Integrate function.

\section{SRS microscopy}

Images were acquired using a custom-built multi-modal microscope setup. A picoEmerald (APE, Berlin, Germany) laser provided both a tunable pump laser (720$990 \mathrm{~nm}, 7 \mathrm{ps}, 80 \mathrm{MHz}$ repetition rate) and a spatially and temporally overlapped Stokes laser (1064 nm, 5-6 ps, $80 \mathrm{MHz}$ repetition rate). The output beams were inserted into the scanning unit of an Olympus FV1000MPE microscope using a series of dielectric mirrors and a 2 lens based beam-expanding module. The resulting $2.4 \mathrm{~mm}$ beams were expanded by a further 3.6 lens within the microscope and directed into an Olympus XLPL25XWMP N.A. 1.05 objective lens using a shortpass $690 \mathrm{~nm}$ dichroic mirror (Olympus). The objective was under-filled to achieve higher power transmissions through the microscope, which were shown to be essential to detecting the SRS signal. Backscattered emission signals from twophoton fluorescence were separated from any backscattered excitation light using a short-pass $690 \mathrm{~nm}$ dichroic mirror and IR cut filter (Olympus). A series of filters and dichroic mirrors were then used to deconvolve the different emission signals onto one of 4 available photo-multiplier tubes (PMT).

For SRS measurements, the Stokes beam was modulated with a $20 \mathrm{MHz}$ EoM built into the picoEmerald. Forward scattered light was collected by a 20 Olympus XLUMPLFLN N.A. 1.00 objective lens and Stokes light was removed by filtering with an ET890/220m filter (Chroma). A telescope focused the light onto an APE silicon photodiode connected to an APE lock in amplifier with the time constant set to $20 \mu \mathrm{s}$. The lock in amplifier signal was fed into an Olympus FV10-Analog unit. Laser powers after the objective were measured up to $40-70 \mathrm{~mW}$ for the pump laser and up to $70 \mathrm{~mW}$ for the Stokes laser. All images were recorded at 512 $\times 512$ or $1024 \times 1024$ pixels with a pixel dwell time between 2 and $20 \mu$ s, using FluoView FV10-ASW scanning software (Olympus). Images of the EdU distribution were recorded at $2120 \mathrm{~cm}^{-1}$ and are presented following removal of background signal using the Image Calculate function on ImageJ $\left(2120-2109 \mathrm{~cm}^{-1}\right)$. False colour LUTs and scale bars were applied to images using ImageJ software.

\section{Chemicals and reagents}

All chemicals were received from commercial suppliers unless otherwise noted, and were used as received without further purification. EdU (Thermo 
Fisher Scientific), $\mathrm{CuSO}_{4} \cdot 5 \mathrm{H}_{2} \mathrm{O}$, Tris-buffered saline (TBS), Tris-HCl, ascorbic acid, sodium ascorbate and biotin-PEG3-azide were all received from Sigma Aldrich.

\section{Kinetic measurements}

Ligand-free CuAAC reaction (IR). A solution of DMSO $(3.32 \mu \mathrm{L})$ and TBS (4.48 $\mu \mathrm{L})$ containing EdU ( $450 \mathrm{mM}, 5 \mu \mathrm{L}$ from $2.0 \mathrm{M}$ stock in DMSO) and biotin-PEG3azide ( $450 \mathrm{mM}, 5 \mu \mathrm{L}$ from $2.0 \mathrm{M}$ stock in DMSO) was treated with $\mathrm{CuSO}_{4}(10 \mathrm{mM}$, $2.2 \mu \mathrm{L}$ from $100 \mathrm{mM}$ stock in water) and sodium ascorbate $(10 \mathrm{mM}, 2.2 \mu \mathrm{L}$ from $100 \mathrm{mM}$ stock in water), added last to the mixture. The $22.2 \mu \mathrm{L}$ mixture was mixed by gentle agitation and vortex mixing before a sample $(0.25 \mu \mathrm{L})$ was removed every 4 minutes and analysed upon the ATR attachment.

Ligand-free CuAAC reaction (Raman). A solution of DMSO $(18 \mu \mathrm{L})$ containing EdU (50 mM, $2.5 \mu \mathrm{L}$ from $500 \mathrm{mM}$ stock in DMSO) and biotin-PEG3-azide (50 mM, $2.5 \mu \mathrm{L}$ from $500 \mathrm{mM}$ stock in DMSO) was treated with $\mathrm{CuSO}_{4}$ ( $4 \mathrm{mM}, 1 \mu \mathrm{L}$ from $100 \mathrm{mM}$ stock in water) and ascorbic acid $(20 \mathrm{mM}, 1 \mu \mathrm{L}$ from $500 \mathrm{mM}$ stock in water), added last to the mixture. The $25 \mu \mathrm{L}$ mixture was mixed by gentle agitation and vortex mixing before a sample $(0.25 \mu \mathrm{L})$ was removed every 4 minutes and analysed using spontaneous Raman spectroscopy. Control reaction mixtures were prepared by varying the biotin azide content (replacing with $2.5 \mu \mathrm{L}$ DMSO) or by varying the $\mathrm{CuSO}_{4}$ content (replacing with $1 \mu \mathrm{L}$ water). Where increased biotin azide concentrations were used, the volume of DMSO was reduced to ensure the total sample volume remained at $25 \mu \mathrm{L}$.

Ligand-assisted CuAAC reaction (Raman). A solution of DMSO $(2 \mu \mathrm{L})$ and water $(1 \mu \mathrm{L})$ containing EdU $(100 \mathrm{mM}, 2 \mu \mathrm{L}$ from $500 \mathrm{mM}$ stock in DMSO) and biotinPEG3-azide (100 mM, $2 \mu \mathrm{L}$ from $500 \mathrm{mM}$ stock in DMSO) was treated with $\mathrm{CuSO}_{4}$ : THPTA ( $5 \mathrm{mM}, 1 \mu \mathrm{L}$ from a pre-mixture comprising $5 \mu \mathrm{L} \mathrm{CuSO}_{4}(100 \mathrm{mM}$ stock in water) $+1 \mu \mathrm{L}$ THPTA ( $500 \mathrm{mM}$ stock in DMSO) $+4 \mu \mathrm{L}$ water) and sodium ascorbate $(100 \mathrm{mM}, 2 \mu \mathrm{L}$ from $0.5 \mathrm{M}$ stock in water), added last to the mixture. The $10 \mu \mathrm{L}$ mixture was mixed by gentle agitation and vortex mixing before a sample $(0.25 \mu \mathrm{L})$ was removed every 2 minutes and analysed using spontaneous Raman spectroscopy. Control reaction mixtures were prepared by varying the biotinPEG3-azide content (replacing with $2 \mu \mathrm{L}$ DMSO) or by varying the $\mathrm{CuSO}_{4}$ content (replacing $\mathrm{CuSO}_{4}$ in the pre-mixture with $5 \mu \mathrm{L}$ water). Where increased biotin-PEG3-azide/EdU/CuSO ${ }_{4}$ concentrations were used, the volume of DMSO was reduced to ensure the total sample volume was consistent and contained a final concentration of DMSO : water of $3: 2 \mathrm{v} / \mathrm{v}$.

Glaser-Hay reaction (Raman). A solution of DMSO $(14 \mu \mathrm{L})$ containing phenylacetylene (100 mM, $4 \mu \mathrm{L}$ from $500 \mathrm{mM}$ stock) was reacted with CuI/TMEDA $(10 \mathrm{mM}, 2 \mu \mathrm{L}$ of a catalyst pre-mixture comprising $10 \mu \mathrm{L} \mathrm{CuI}(500 \mathrm{mM}$ stock in DMSO) $+10 \mu \mathrm{L}$ TMEDA (500 mM in DMSO $)+30 \mu \mathrm{L}$ DMSO). The reaction mixture (20 $\mu \mathrm{L}$ in an Eppendorf tube) was vortex-mixed and a constant flow of air was bubbled through it using a capillary needle from an air-filled balloon for the duration of the reaction timecourse. Samples were removed every 2 minutes and analysed using spontaneous Raman spectroscopy. Control reaction mixtures were prepared by varying the [CuI] (replacing with $5 \mu \mathrm{L}$ DMSO in the pre-mixture). All reactions were carried out in DMSO at a final volume of $20 \mu \mathrm{L}$. 


\section{Kinetic analysis}

The spectra were baseline corrected using the Baseline subtract function available on WiRE TM software. The spectra were then normalised to the area of the peak at $1420 \mathrm{~cm}^{-1}$ (CH def. DMSO, area: $1380-1460 \mathrm{~cm}^{-1}$; Raman), or the intensity of the peak at $2920 \mathrm{~cm}^{-1}$ (C-H, DMSO, IR). After this, the spectra were either overlaid for comparison or the peak area at $2096 \mathrm{~cm}^{-1}\left(\mathrm{~N}_{3}\right.$, CuAAC, area (biotin azide, 2): 2050-2150 $\mathrm{cm}^{-1}$ ), $2120 \mathrm{~cm}^{-1}$ (C $\equiv \mathrm{C}$, CuAAC, area (EdU, 1): 2075-2140 $\mathrm{cm}^{-1}$ ), $2122 \mathrm{~cm}^{-1}$ ( $\mathrm{C} \equiv \mathrm{C}$, Glaser-Hay, area (PC): 2090-2150 $\left.\mathrm{cm}^{-1}\right), 2269 \mathrm{~cm}^{-1}(\mathrm{C} \equiv \mathrm{C}$, Glaser-Hay, area (PC product, 4): 2230-2290 $\mathrm{cm}^{-1}$ ), $2102 \mathrm{~cm}^{-1}(\mathrm{C} \equiv \mathrm{C}$, GlaserHay, area (PA): 2080-2130 $\mathrm{cm}^{-1}$ ) and $2218 \mathrm{~cm}^{-1}$ (C三C, Glaser-Hay, area (PA product, 5): $2180-2240 \mathrm{~cm}^{-1}$ ) was determined using integration analysis available on Origin Software. Data were plotted and fitted using Origin graphic analysis package. Temporal concentrations/mol-fraction data for the CuAAC reaction were fitted to a standard exponential decay using the solver function in Excel, with initial concentration and first-order rate constants as unrestricted variables. Reciprocal temporal concentrations of [PA] were plotted to estimate $k_{\mathrm{obs}}$ for the Glaser-Hay reaction. Errors in rate determinations were estimated as the rootmean square of the difference between $k_{\text {obs }}$ calculated from the analytical rate equation for each datapoint and $k_{\mathrm{obs}}$ obtained by linear-regression of the entire dataset.

\section{Conflicts of interest}

There are no conflicts to declare.

\section{Acknowledgements}

The research leading to these results received funding from the BBSRC (Grant Ref: BB/N021614/1), Cancer Research UK (Grant ref: C157/A25140 and C157/A15703), and the European Research Council under the European Union's Seventh Framework Programme (FP7/2007-2013)/ERC Grant Agreement 340163. We thank Dr Colin Campbell for use of the spontaneous Raman microscope [UK Regenerative Medicine Platform Niche Hub, MR/K026666/1].

\section{Notes and references}

1 (a) E. M. Sletten and C. R. Bertozzi, Angew. Chem., Int. Ed., 2009, 48, 6974-6998;

(b) J. A. Prescher and C. R. Bertozzi, Nat. Chem. Biol., 2005, 1, 13-21.

2 C. S. McKay and M. G. Finn, Chem. Biol., 2014, 21, 1075-1101.

3 N. Krall, F. P. da Cruz, O. Boutureira and G. J. L. Bernardes, Nat. Chem., 2015, 8, 103-113.

4 D. M. Patterson, L. A. Nazarova and J. A. Prescher, ACS Chem. Biol., 2014, 9, 592-605.

5 K. Lang and J. Chin, ACS Chem. Biol., 2014, 9, 16-20.

6 (a) K. Neumann, A. Gambardella, A. Lilienkampf and M. Bradley, Chem. Sci., 2018, 9, 7198-7203; (b) J. Clavadetscher, E. Indrigo, S. V. Chankeshwara, A. Lilienkampf and M. Bradley, Angew. Chem., Int. Ed., 2017, 56, 6864-6868; (c) J. Clavadetscher, S. Hoffmann, A. Lilienkampf, L. Mackay, R. M. Yusop, 
S. A. Rider, J. J. Mullins and M. Bradley, Angew. Chem., Int. Ed., 2016, 55, 1566215666.

7 (a) N. K. Devaraj, ACS Cent. Sci., 2018, 4, 952-959; (b) J. G. Rebelein and T. R. Ward, Curr. Opin. Biotechnol., 2018, 53, 106-114.

8 A. Nadler and C. Schultz, Angew. Chem., Int. Ed., 2013, 52, 2408-2410.

9 K. Sivakumar, F. Xie, B. M. Cash, S. Long, H. N. Barnhill and Q. Wang, Org. Lett., 2004, 6, 4603-4606.

10 S. Sun and P. Wu, J. Phys. Chem. A, 2010, 114, 8331-8336.

11 A. R. Buchberger, K. DeLaney, J. Johnson and L. Li, Anal. Chem., 2018, 90, 240265.

12 M. V. Gomez and A. de la Hoz, Beilstein J. Org. Chem., 2017, 13, 285-300.

13 (a) R. Grima, J. Chem. Phys., 2010, 132, 185102; (b) H.-X. Zhou, G. Rivas and A. P. Minton, Annu. Rev. Biophys., 2008, 37, 375-397.

14 (a) C. Corbet and O. Feron, Nat. Rev. Cancer, 2017, 17, 577-593; (b) S. K. Parks, J. Chiche and J. Pouysségur, Nat. Rev. Cancer, 2013, 13, 611-623.

15 (a) Q. Li, T. Zhou, F. Wu, N. Li, R. Wang, Q. Zhao, Y.-M. Ma, J.-Q. Zhang and B.-L. Ma, Drug Metab. Rev., 2018, 50, 430-447; (b) X. Chu, K. Korzekwa, R. Elsby, K. Fenner, A. Galetin, Y. Lai, P. Matsson, A. Moss, S. Nagar, G. R. Rosania, J. P. F. Bai, J. W. Polli, Y. Sugiyama and K. L. R. Brouwer, Clin. Pharmacol. Ther., 2013, 94, 126-141.

16 (a) B. G. Saar, C. W. Freudiger, J. Reichman, C. M. Stanley, G. R. Holtom and X. S. Xie, Science, 2010, 330, 1368-1370; (b) B. G. Saar, Y. Zeng, C. W. Freudiger, Y.-S. Liu, M. E. Himmel, X. S. Xie and S.-Y. Ding, Angew. Chem., Int. Ed., 2010, 49, 5476-5479.

17 (a) S. Vanden-Hehir, W. J. Tipping, M. Lee, V. G. Brunton, A. Williams and A. N. Hulme, Nanomaterials, 2019, 9, 341; (b) R. C. Prince, R. R. Frontiera and E. O. Potma, Chem. Rev., 2017, 117, 5070-5094; (c) L. Wei, F. Hu, Z. Chen, Y. Shen, L. Zhang and W. Min, Acc. Chem. Res., 2016, 49, 14941502; (d) C. Krafft, I. W. Schie, T. Meyer, M. Schmitt and J. Popp, Chem. Soc. Rev., 2016, 45, 1819-1849; (e) W. J. Tipping, M. Lee, A. Serrels, V. G. Brunton and A. N. Hulme, Chem. Soc. Rev., 2016, 45, 2075-2089.

18 (a) W. J. Tipping, M. Lee, A. Serrels, V. G. Brunton and A. N. Hulme, Chem. Sci., 2017, 8, 5606-5615; (b) F. Hu, M. R. Lamprecht, L. Wei, B. Morrison and W. Min, Sci. Rep., 2016, 6, 39660; (c) S. Hong, T. Chen, Y. Zhu, A. Li, Y. Huang and X. Chen, Angew. Chem., Int. Ed., 2014, 53, 5827-5833; (d) Z. Chen, D. W. Paley, L. Wei, A. L. Weisman, R. A. Friesner, C. Nuckolls and W. Min, J. Am. Chem. Soc., 2014, 136, 8027-8033; (e) L. Wei, F. Hu, Y. Shen, Z. Chen, Y. Yu, C.-C. Lin, M. C. Wang and W. Min, Nat. Methods, 2014, 11, 410-414.

19 (a) V. V. Rostovtsev, L. G. Green, V. V. Fokin and K. B. Sharpless, Angew. Chem., Int. Ed., 2002, 41, 2596-2599; (b) C. W. Tornoe, C. Christensen and M. Meldal, J. Org. Chem., 2002, 67, 3057-3064.

20 H. C. Kolb and K. B. Sharpless, Drug Discovery Today, 2003, 8, 1128-1137.

21 A. S. Hay, J. Org. Chem., 1962, 27, 3320-3321.

22 Z. M. Nimmo, J. F. Halonski, L. E. Chatkewitz and D. D. Young, Bioorg. Chem., 2018, 76, 326-331.

23 S. I. Presolski, V. Hong, S.-H. Cho and M. G. Finn, J. Am. Chem. Soc., 2010, 132, 14570-14576. 
24 C. R. Travis, L. E. Mazur, E. M. Peairs, G. H. Gaunt and D. D. Young, Org. Biomol. Chem., 2019, 17, 3396-3402.

25 N. Li, K. Reyna, V. Lim, S. Edwardraja and Q. Lin, J. Am. Chem. Soc., 2011, 133, 15316-15319.

26 M. F. Debets, S. S. Van Berkel, J. Dommerholt, A. J. Dirks, F. P. J. T. Rutjes and F. L. Van Delft, Acc. Chem. Res., 2011, 44, 805-815.

27 (a) K. Lang, L. Davis, S. Wallace, M. Mahesh, D. J. Cox, M. L. Blackman, J. M. Fox and J. W. Chin, J. Am. Chem. Soc., 2012, 134, 10317-10320; (b) W. Chen, D. Wang, C. Dai, D. Hamelberg and B. Wang, Chem. Commun., 2012, 48, 1736-1738.

28 H. C. Kolb, M. G. Finn and K. B. Sharpless, Angew. Chem., Int. Ed., 2001, 40, 2004-2021.

29 (a) B. T. Worrell, J. A. Malik and V. V. Fokin, Science, 2013, 340, 457-460; (b) R. Chung, A. Vo, V. V. Fokin and J. E. Hein, ACS Catal., 2018, 8, 7889-7897.

30 L. Zhu, C. J. Brassard, X. Zhang, P. M. Guha and R. J. Clark, Chem. Rec., 2016, 16, 1501-1517.

31 C. P. Seath, G. A. Burley and A. J. B. Watson, Angew. Chem., Int. Ed., 2017, 56, 3314-3318.

32 C. Glaser, Ber. Dtsch. Chem. Ges., 1869, 2, 422-424.

33 P. Siemsen, R. C. Livingston and F. Diederich, Angew. Chem., Int. Ed., 2000, 39, 2632-2657.

34 F. Bohlmann, H. Schönowsky, E. Inhoffen and G. Grau, Chem. Ber., 1964, 97, 794-800.

35 M. H. Vilhelmsen, J. Jensen, C. G. Tortzen and M. B. Nielsen, Eur. J. Org. Chem., 2013, 701-711.

36 J. Jover, P. Spuhler, L. Zhao, C. McArdle and F. Maseras, Catal. Sci. Technol., 2014, 4, 4200-4209.

37 H. J. Butler, L. Ashton, B. Bird, G. Cinque, K. Curtis, J. Dorney, K. EsmondeWhite, N. J. Fullwood, B. Gardner, P. L. Martin-Hirsch, M. J. Walsh, M. R. McAinsh, N. Stone and F. L. Martin, Nat. Protoc., 2016, 11, 664-687.

38 A. Salic and T. J. Mitchison, Proc. Natl. Acad. Sci. U. S. A., 2008, 105, 2415-2420.

39 A. E. Kliszczak, M. D. Rainey, B. Harhen, F. M. Boisvert and C. Santocanale, Sci. Rep., 2011, 1, 95.

40 J. E. Hein and V. V. Fokin, Chem. Soc. Rev., 2010, 39, 1302-1315.

41 V. O. Rodinov, S. I. Presolski, D. Diaz Diaz, V. V. Fokin and M. G. Finn, J. Am. Chem. Soc., 2007, 129, 12705-12712.

42 D. C. Kennedy, C. S. McKay, M. C. B. Legault, D. C. Danielson, J. A. Blake, A. F. Pegoraro, A. Stolow, Z. Mester and J. P. Pezacki, J. Am. Chem. Soc., 2011, 133, 17993-18001.

43 J. S. Lampkowski, J. K. Villa, T. S. Young and D. D. Young, Angew. Chem., Int. Ed., 2015, 54, 9343-9346.

44 J. C. Maza, J. R. McKenna, B. K. Raliki, M. T. Freedman and D. D. Young, Bioconjugate Chem., 2015, 26, 1884-1889.

45 J. S. Lampkowski, D. M. Uthappa, J. C. Maza and D. D. Young, J. Org. Chem., 2016, 81, 12520-12524.

46 C. Y. Jao, M. Roth, R. Welti and A. Salic, Proc. Natl. Acad. Sci. U. S. A., 2009, 106, 15332-15337.

47 R. Bai, G. Zhang, H. Yi, Z. Huang, X. Qi, C. Liu, J. T. Miller, A. J. Kropf, E. E. Bunel, Y. Lan and A. Lei, J. Am. Chem. Soc., 2014, 136, 16760-16763. 